\title{
DEMANDAS DA AVALIAÇÃO DA APRENDIZAGEM NA EDUCAÇÃO A DISTÂNCIA NA PERSPECTIVA DA EDUCAÇÃO SUPERIOR
}

\author{
Vialana Ester Salatino \\ Andréia Morés
}

Resumo

Contempla-se um rastreamento teórico da avaliação da aprendizagem no contexto da Educação a Distância (EaD), na perspectiva da educação superior. Com base no atual cenário brasileiro, considera-se a importância de investir na emancipação dos educandos, devido às mudanças e à mercantilização da educação, que abrevia a formação para a autonomia e transforma seus atores em oprimidos. Objetiva-se compreender o cenário educativo superior que permeia a avaliação na EaD. Aponta-se a avaliação como contribuição para processos de ensino e aprendizagem na modalidade EaD, permeada por tecnologias, e visa à autonomia dos educandos além dos conhecimentos adquiridos. A educação superior passa por mudanças, e a EaD expande-se significativamente, pressionada pelas características de mercado.

Palavras-chave: avaliação da aprendizagem; educação a distância; educação superior.

\section{DEMANDS OF LEARNING EVALUATION IN DISTANCE EDUCATION IN THE PERSPECTIVE OF HIGHER EDUCATION}

\begin{abstract}
It is considered a theoretical tracking of the of learning's evaluation in the context of Distance Learning from the perspective of higher education. Based on the current Brazilian scenario, considering the importance of ivesting in the students' emancipation due to changes and education's commodification, which abbreviates the formation for autonomy and transforms its actors into oppressed. It aims to understand the higher educational scenario that conducts an evaluation in Distance Learning. It is pointed out the evaluation as a contribution to teaching and learning processes in the Distance Learning modality, permeated by technologies and address to the autonomy of students beyond the acquired knowledge. Higher education is undergoing changes and Distance Learning expands significantly, pressured by market characteristics.
\end{abstract}

Keywords: learning evaluation; distance learning; higher education.

\section{DEMANDAS DE LA EVALUACIÓN DEL APRENDIZAJE EN LA EDUCACIÓN A DISTANCIA EN LA PERSPECTIVA DE LA EDUCACIÓN SUPERIOR}

Resumen

Se considera un seguimiento teórico de la evaluación del aprendizaje en el contexto de la Educación a Distancia (DE) desde la perspectiva de la educación superior. Se basa en el escenario brasileño actual, considerando la importancia de invertir em la emancipación de los estudiantes debido a los cambios y la mercantilización de la educación, lo que acorta la formación para la autonomía y transforma a sus actores em oprimidos. Apunta a comprender el escenario de educación superior que realiza una evaluación en DE. Acepta una evaluación como contribución a los procesos de enseñanza y aprendizaje en la educación a distancia habilitada por la tecnología y apunta a la autonomía de los estudiantes más allá del conocimiento adquirido. La educación superior está experimentando cambios y la educación a distancia se expande significativamente, presionada por las características del mercado.

Palabras clave: evaluación del aprendizaje; educación a distancia; educación universitaria. 


\section{INTRODUÇÃO}

Neste artigo, apresenta-se um estudo reflexivo sobre as contribuições da avaliação da aprendizagem na Educação a Distância (EaD), no Ensino Superior. Conforme dados divulgados pelo Censo da Educação Superior 2018 do Ministério da Educação, Instituto Nacional de Estudos e Pesquisas Educacionais Anísio Teixeira (MEC/INEP), o número de vagas oferecidas dobrou em um período de quatro anos.

Ao se pensar em avaliação da aprendizagem, no contexto do Ensino Superior e da EaD, é necessário refletir sobre as concepções e visões que contribuem para qualificar a avaliação. A avaliação se faz necessária, no Ensino Superior e na universidade, pois somente assim é possível perceber a qualidade dos processos de ensino, das políticas públicas e ainda identificar sujeitos emancipados. Para Dias Sobrinho (2008, p. 193), “[...] avaliação é produção de sentidos, prática social”. O autor considera a avaliação algo mais amplo, vinculado à formação de sentidos.

Além das contribuições de Dias Sobrinho (2008), Santos (2011) embasa os conceitos de universidade do século XXI, articulando-os com os estudos de Paulo Freire, sobre os conceitos de autonomia e oprimido, assim como com os de outros autores que colaboram com essa temática e que vão surgindo ao longo do texto.

Ao discutir sobre isto, é necessário pensar a respeito das modificações pelas quais passam as Instituições de Ensino Superior em sua essência e acerca das demandas avaliativas da EaD. Portanto, entende-se que existem diferentes práticas de avaliação e que esse ato, em si, tende a despertar reflexão sobre o que é adequado avaliar. Pode ser difícil avaliar a aprendizagem e, na $\mathrm{EaD}$, isso se torna uma responsabilidade ainda maior, dado que na avaliação, de modo subjetivo, mensura-se também a qualidade da Educação a Distância.

O estudo sobre o contexto da avaliação da aprendizagem foi realizado através do aporte teórico apresentado no texto, que considerou, metodologicamente, pesquisa bibliográfica sobre esse tema, de acordo com o que apresenta Paviani (2009, p. 125). Ele considera que "[...] o quadro teórico consiste na articulação racional de conceitos e proposições, de diversos autores ou teorias, que orientam a investigação, justificando a escolha do método e de outros procedimentos". Constatou-se relação entre os levantamentos teóricos aqui apresentados, com vistas a entendimentos e considerações iniciais, contando com a análise de conteúdo de Bardin (2004). A técnica de Bardin foi utilizada no que tange às inferências das autoras, sendo apenas instituídas pautas de observação e não categorias de análise, visando - a práticas avaliativas na $\mathrm{EaD}$ (e se existe) - à inovação nas práticas avaliativas. A pauta de observação, previamente estruturada, não pretende limitar possíveis categorias que venham a emergir com as respostas obtidas nos questionários, mas colabora com a análise dos dados que serão construídas durante a investigação.

Com base no exposto, estrutura-se o artigo a partir dos seguintes itens: avaliação da aprendizagem; reflexão sobre a avaliação da aprendizagem na EaD; explanação sobre a perspectiva da educação superior e, posteriormente, a conclusão do artigo.

\section{AVALIAÇÃO DA APRENDIZAGEM}

Ao pensar na avaliação da aprendizagem, tem-se a clara noção de que professores sempre buscam melhorar sua prática avaliativa, e Dias Sobrinho (2008, p. 198) defende a avaliação educativa com o critério de que deverá ser educativa em si mesma, afinal, quando um professor avalia, seu processo de ensino também está em avaliação. De acordo com esse autor, “[...] tudo na educação tem interesse à avaliação", porque não há como separar a avaliação do processo de educação; não existe, assim, compreensão para avaliar isoladamente; também não há educação que 
não contemple avaliar. Isto porque uma não existe sem a outra, ou seja, avalia-se para ensinar e, ao ensinar, é necessário avaliar para perceber o resultado desse ensinar, que nada mais é do que a aprendizagem que proporciona emancipação ao aprendente. (DIAS SOBRINHO, 2008).

Por sua vez, Saul $(1994$, p. 63) diz que “[...] os professores não estão satisfeitos (salvo exceções) com a avaliação que fazem". Essa autora enfatiza que, para que os professores mudem, melhorem o processo de avaliação, este deverá estar vinculado à melhoria da qualidade de ensino em si. Justifica que "[...] a avaliação é intrinsicamente ligada ao processo pedagógico que nós estamos desenvolvendo" (SAUL, 1994, p. 64), na condição de professores.

No processo de aprendizagem, está inserida a avaliação cuja finalidade pressupõe a emancipação e a autonomia dos avaliados, a partir dos conhecimentos compartilhados e da aprendizagem construída. Refletir sobre isso é compreender concepções envolvidas, perceber processos e estabelecer boas práticas, e deve-se estar atento para não ser injusto ao avaliar.

Conforme Luckesi (2008, p. 20), “[...] os acontecimentos do processo de ensino e aprendizagem, seja para analisá-los criticamente, seja para encaminhá-los de uma forma mais significativa e vitalizante, permanecem adormecidos em um canto". Até porque parece que tudo continua igual ao que sempre foi, provas e trabalhos valem a aprovação ou reprovação, porque são necessários. Mas, pergunta-se: como fica a avaliação dos processos de ensino e aprendizagem? Será que é preciso avaliar apenas para aprovar, promover, ou é o contrário? Como não é fácil avaliar nem mesmo pensar sobre isso, parece que a zona de conforto prevalece e existe a tendência de o processo de avaliação do ensino permanecer como sempre foi.

De acordo com Dias Sobrinho (2008, p. 196), “[...] se educar é formar para a vida social, essa deve ser a matéria principal da avaliação". Ressalta que a reflexão, no sentido da avaliação, ocorre quando "[...] o professor reflete sobre sua própria prática, ou de forma coletiva, quando a reflexão se socializa e envolve diversos conjuntos de atores institucionais". (DIAS SOBRINHO, 2008, p. 197). Nesse caso, pode existir a troca entre as partes, em uma visão sistêmica, mais ampla, que envolva não apenas o processo de ensinar e aprender, mas também a formação cidadã e emancipatória.

Destaca-se a importância de se refletir sobre o processo de avaliação, especialmente sobre qual é o papel do aluno, do professor ou da universidade acerca dos processos avaliativos utilizados, bem como observar se o resultado obtido com o que foi avaliado é essencial para a melhoria da educação e da avaliação. (SAUL, 1994).

Um importante momento da prática pedagógica é a avaliação da aprendizagem. Para o entendimento da avaliação da aprendizagem, Perrenoud (1999, p. 28) referenda:

O êxito e o fracasso escolares resultam do julgamento diferencial que a organização escolar faz dos alunos, da base de hierarquias de excelência estabelecidas em momentos do curso que ela escolhe e conforme procedimentos de avaliação que lhe pertencem.

Percebe-se, inicialmente, nesse trecho, um destaque ao poder subjetivo da instituição e do professor que, embora se refira à escola, serve bem ao Ensino Superior, ou até melhor. Essa abordagem, segundo o autor, gera maior valorização do produto e não do processo de aprendizagem propriamente. (PERRENOUD, 1999).

Por esse motivo, a avaliação, como instrumento de poder, também é referendada por Bourdieu (1977), ao abordar a posição dos alunos como meros subordinados ao poder da instituição escolar e do professor. Tal subordinação se manifesta através da visão do professor como o detentor do capital cultural, o qual cria subordinação mediante os processos de avaliação que se tornam instrumentos de punição ou de manutenção do poder. Para superar essa visão da 
avaliação, enquanto instrumento de poder, acrescem-se as contribuições de Luckesi (2008, p. 81): "A avaliação deverá ser assumida como um instrumento de compreensão do estágio de aprendizagem em que se encontra o aluno, tendo em vista tomar decisões suficientes e satisfatórias, para que se possa avançar no seu processo de aprendizagem".

De acordo com o autor (2008), a avaliação deve possibilitar a aprendizagem do aluno; oportunizar tomadas de decisão, tornando-o crítico, capaz de intervir e avançar no seu processo de aprendizagem. Conforme Dias Sobrinho (2008, p. 198), a ênfase da avaliação é a formação de seres humanos, preparados para uma sociedade "mais elevada, justa e digna". O mesmo autor assim define os fins da educação: "[...] a formação cidadã-profissional-ética-moral-política-técnica; a elevação e o desenvolvimento material, cultural, espiritual da sociedade; o avanço da ciência e o fortalecimento dos valores democráticos". Desse modo, aumenta a responsabilidade que se tem com a prática avaliativa, afinal é esta que identificará se o aluno se tornou esse ser emancipado, desenvolvido ou não. Mas, também, é ela que possibilita ensinar o que não se entende como efetivo na própria prática avaliativa.

Seguindo esse pensamento, apresentam-se algumas concepções de avaliação, que contribuem para qualificar os processos de ensino e aprendizagem. Traz-se a visão de Haydt (1997), que destaca que a avaliação pode ser diagnóstica, formativa ou somativa. Por avaliação diagnóstica, a autora compreende a investigação das razões dos fracassos na prática educativa, através da identificação da presença ou ausência de pré-requisitos e a existência de dificuldades específicas de aprendizagem. Esse tipo de avaliação acontece no início do ano, do semestre letivo e no início de uma nova unidade de ensino. Em relação à avaliação formativa, a autora compreende que é uma prática realizada enquanto se executa uma atividade, ou seja, durante o semestre letivo, e visa a acompanhar o andamento dos objetivos, além de orientar o aperfeiçoamento do processo. Por fim, a avaliação somativa compreende, no final, que permite uma certificação da atividade, expressando, de certa forma, sua validação.

Ao comentar os tipos de avaliação citados por Haydt (1997), Santos et al. (2005) acrescentam a avaliação cumulativa e a autoavaliação. De acordo com o autor, a avaliação cumulativa consiste em uma concentração que vai ocorrendo ao longo do processo, com o acompanhamento do professor (semelhante à avaliação formativa); já a autoavaliação é realizada pelo próprio aluno, mesmo que estimulada pelo professor, e funciona como uma tomada de consciência para melhorar a aprendizagem. Para Santos et al. (2005), a aprendizagem é complexa; é muito mais do que uma atribuição de nota relacionada a uma prova, pois ela está, diz o autor, atrelada ao movimento de aprendizagem.

Conforme Libâneo (1994, p. 195), a avaliação é um ato reflexivo sobre a qualidade do trabalho do professor e dos alunos. Caracteriza-se como uma tarefa permanente e necessária do fazer didático do professor, e caminha de acordo com o andamento do ensino e da aprendizagem, pois, "[...] através dela, os resultados que vão sendo obtidos no decorrer do trabalho conjunto do professor e dos alunos são comparados com os objetivos propostos, a fim de constatar progressos, dificuldades, e reorientar o trabalho para as correções necessárias".

A visão de Libâneo (1994) propõe a superação da avaliação classificatória, que serve apenas para aprovar, reprovar ou para classificar. Defende que a avaliação contribui para o desenvolvimento dos sistemas de ensino e aprendizagem. Nessa visão, a avaliação também serve para mediar a aprendizagem, pois diz Hoffmann (1997, p. 191): “A ação avaliativa mediadora se desenvolve em benefício do educando e dá-se fundamentalmente pela proximidade entre quem educa e quem é educado". É um modo contínuo de ação-reflexão-ação, ou seja, o professor e o aluno agem acerca da aprendizagem, refletem sobre seu resultado. Caso este não seja considerado bom, realizam outras ações objetivando atingi-la. 
Destaca-se, aqui, a avaliação emancipatória, proposta por Saul (1994, p. 1309): opõe-se "[...] a oposição à avaliação da lógica do controle, de acordo com uma educação crítico libertadora", pois, com base nos pressupostos que permeiam a avaliação "[...] democrática, a crítica institucional, a criação coletiva e a pesquisa participante constitui-se [...] matriz praxiológica que descreve, analisa e critica uma dada realidade, visando transformá-la?" Para a autora, a avaliação emancipatória está "comprometida com o futuro" e com o que se pretende transformar dentro da realidade que existe; defende ainda o desenvolvimento de uma consciência crítica. A avaliação emancipatória se baseia na tríade: decisão democrática, transformação, e crítica educativa, embora não desconsidere a avaliação quantitativa, mas tenha um foco maior na educação qualitativa. (SAUL, 2015).

Essas visões sobre avaliação qualificam os processos de ensino e aprendizagem na educação superior em EaD. As contribuições de Hoffman (2005, p. 17) revelam que a avaliação é a reflexão transformada em ação. Ação que "[...] nos impulsiona a novas reflexões. Reflexão permanente do educador sobre sua realidade, e acompanhamento de todos os passos do educando, na sua trajetória de construção do conhecimento".

\section{AVALIAÇÃO DA APRENDIZAGEM NA EAD}

Ao se referir sobre a avaliação da aprendizagem na $\mathrm{EaD}$, pensa-se em uma prática cada vez mais recorrente, pois a expansão da modalidade ocorre acelerada no Brasil e no mundo. No Brasil, no entanto, é possível ter uma noção dessa expansão, no número de vagas oferecidas em cursos de graduação, por modalidade de ensino, no período de 2014 a 2018: em 2014 havia 5.038.392 vagas presenciais e na $\mathrm{EaD} 3.042 .977$; já em 2018 havia no presencial 6.358.534 e na EaD superou-se o número de vagas com um total de 7.170.567. Destaca-se que o número de vagas nesta modalidade dobrou de 2014 para 2018, conforme os dados do Censo da Educação Superior 2018, do MEC/Inep, pois não está disponível o de 2019 até o presente momento.

O que fica comprovado no enunciado a seguir:

O número de ingressos, em cursos de graduação a distância, tem crescido substancialmente nos últimos anos, dobrando sua participação, no total de ingressantes, de $20 \%$ em 2008 para $40 \%$ em 2018. Nos últimos 5 anos, os ingressos, nos cursos de graduação presenciais, diminuíram 13\%. (MEC/Inep, 2018, p. 18).

A EaD rapidamente cresce e, com isso, ocorre uma redução nas vagas presenciais nos cursos já existentes. Porém, observa-se que essa modalidade amplia o ingresso à educação, especialmente em locais distantes, em que é difícil o acesso às instituições educacionais presenciais.

Ainda de acordo com a modalidade de ensino, os dados do Censo da Educação Superior de 2018 indicam que existem cerca de 3.177 na modalidade $\mathrm{EaD}$ e 34.785 em cursos presenciais, e ainda que se tem 1.373.321 ingressantes na EaD contra 2.072.614 ingressantes no ensino presencial. Destes são concluintes 273.873 na EaD e 990.415 no presencial. Estes dados também nos remetem a pensar sobre a $\mathrm{EaD}$ e suas práticas avaliativas, afinal podem ser geradoras de evasão ou permanência.

Assim, faz-se menção ao apoio das políticas educacionais para o fortalecimento e a qualidade da EaD no Brasil. Destaca-se o Decreto n. 5.622, de 19 de dezembro de 2005, que regulamenta o Art. 80 da Lei n. 9.394, de 20 de dezembro de 1996, que estabelece as diretrizes e bases da educação nacional:

Art. $1^{\circ}$. Para os fins deste Decreto, caracteriza-se a educação a distância como modalidade educacional na qual a mediação didático-pedagógica nos processos 
de ensino e aprendizagem ocorre com a utilização de meios e tecnologias de informação e comunicação, com estudantes e professores desenvolvendo atividades educativas em lugares ou tempos diversos.

$\mathrm{Na}$ sequência do Capítulo 1, Art. $1^{\circ}$ e Inciso primeiro, preceitua que “[...] a educação a distância organiza-se segundo metodologia, gestão e avaliação peculiares, para as quais deverá estar prevista a obrigatoriedade de momentos presenciais" (s/n), isso em relação às avaliações, aos estágios obrigatórios, à defesa de trabalhos de conclusão de curso e a práticas de laboratório.

E no Inciso II acrescenta que à avaliação presencial deve "[...] prevalecer sobre os demais resultados obtidos em quaisquer outras formas de avaliação a distância" (s/n), o que valoriza a efetiva participação do estudante no processo de aprendizagem.

Mas destaca-se que o Decreto n. 5.622, de 19 de dezembro de 2005 foi revogado pelo Decreto n. 9.057, de 25 de maio de 2017, e este, como anteriormente mencionado, estabelece normativas semelhantes para a avaliação na $\mathrm{EaD}$. No entanto, flexibiliza também o estabelecimento de polos da EaD.

A avaliação da aprendizagem na modalidade $\mathrm{EaD}$ apresenta características peculiares e particularidades para além do uso de recursos tecnológicos. O Decreto n. 9.057, de 25 de maio de 2017, estabelece mudanças na legislação pertinente à Educação a Distância e dispõe, no Capítulo I das Disposições Gerais, no seu art. $1^{\circ}$ :

Para os fins deste Decreto, considera-se educação a distância a modalidade educacional na qual a mediação didático-pedagógica nos processos de ensino e aprendizagem ocorra com a utilização de meios e tecnologias de informação e comunicação, com pessoal qualificado, com políticas de acesso, com acompanhamento e avaliação compatíveis, entre outros, e desenvolva atividades educativas por estudantes e profissionais da educação que estejam em lugares e tempos diversos. (BRASIL, 2017, s. p.).

Como é evidente, este art. $1^{\circ}$ regula e autoriza a $\mathrm{EaD}$ no País, delineando sua forma de funcionamento. Já em relação ao art. $4^{\circ}$, que dispõe sobre as atividades específicas que precisam ser realizadas nos polos, decreta:

As atividades presenciais, como tutorias, avaliações, estágios, práticas profissionais e de laboratório e defesa de trabalhos, previstas nos projetos pedagógicos ou de desenvolvimento da instituição de ensino e do curso, serão realizadas na sede da instituição de ensino, nos polos de educação a distância ou em ambiente profissional, conforme as Diretrizes Curriculares Nacionais. (BRASIL, 2017, s. p.).

Com isso, a legislação prevê momentos avaliativos presenciais na $\mathrm{EaD}$, que garantem que o aluno é quem está realmente realizando a avaliação, pois, se fosse somente a distância, não haveria como comprovar que quem responde aos critérios avaliativos é o próprio aluno. Esse é um ponto fundamental na avaliação na $\mathrm{EaD}$, e que interessa a este estudo.

Mas, como nem todo o processo avaliativo necessita resultar em nota, várias são as possibilidades de avaliar por meio de tecnologias diversas, até mesmo a título de compreender o avanço de conhecimento sobre temas que os alunos estão tendo. Assim, orienta também o processo de ensino, e contribui para os professores qualificarem suas práticas.

Para Vygotsky (1998), a interação ocorre por meio de instrumentos e signos, que estão inseridos no processo de mediação, fundamental para o desenvolvimento do aprendizado. $\mathrm{Na}$ modalidade EaD, existe a utilização de ambientes virtuais de aprendizagem (AVAs) e ferramentas que visam a construir a interação entre os alunos e a organizar os processos de avaliação da 
aprendizagem, por meio das tecnologias que representam os instrumentos externos, aos quais Vygotsky (1998) se refere. Destaca-se que a avaliação é também um processo construtivo do aprendizado do aluno; em fóruns de discussão, por exemplo, pode-se avaliar em grupos, ou por meio da interação social, mesmo a distância, em tempos e locais particulares a cada aluno.

Entende-se que, na avaliação e no trabalho pedagógico, encontra-se uma série de caminhos diferenciados a percorrer, que integram o modo de avaliação da aprendizagem (DILIGENTI, 2003), ou os modelos de avaliação utilizados por instituições de Ensino Superior na modalidade $\mathrm{EaD}$, como forma de compreender os exemplos e as práticas que busquem entender e aplicar uma avaliação dialógica, conforme define Hoffmann (1994, p. 56):

A avaliação, enquanto relação dialógica, [...] vai conceber o conhecimento como apropriação do saber pelo aluno e também pelo professor, como ação-reflexãoação que se passa na sala de aula em direção a um saber aprimorado, enriquecido, carregado de significados, de compreensão.

A avaliação dialógica estabelece uma conversa entre o professor e o aluno, e nessa conversação há a possibilidade de aprendizado mútuo e de avaliação daquilo que foi aprendido. Esse diálogo proporciona desenvolvimento para quem aprende, que, ao aprender, se emancipa, e pode se tornar autônomo. Com isso não mais será refém da sociedade, mas um sujeito ativo nela. Isso pode ocorrer tanto ao professor quanto ao aluno. $\mathrm{Na} \mathrm{EaD}$, a avaliação dialógica que conduz à emancipação pode ocorrer por meio de recursos, como fóruns, chats e ainda através de mensagens e e-mails, um pouco diferente da presencial, mas ainda assim possível.

Uma sala de aula virtual, por ser em modalidade de $\mathrm{EaD}$, não deve perder sua característica emancipatória. Para Dias Sobrinho (2008, p. 195): “A educação superior é instrumento de aprofundamento e fortalecimento de autonomia pessoal, da emancipação do sujeito, mediante as relações com os valores, o conhecimento, a crítica, a reflexão, o exercício político da participação na vida da sociedade".

Tais características deverão ser mantidas, com ou sem o uso das tecnologias e dos ambientes virtuais, uma vez que avaliar é perceber o desenvolvimento dos avaliados, em termos dos objetivos que se tinha com a aprendizagem.

A constante evolução das tecnologias afeta também a educação, visto que as "[...] tecnologias alteram todas as nossas ações, as condições de pensar e representar a realidade e, especificamente, no caso particular da educação, a maneira de trabalhar as atividades ligadas à educação". (KENSKI, 2008, p. 29).

No início das atividades de EaD, percebia-se a simples transposição de metodologias da modalidade presencial para a modalidade a distância, sem uma adaptação tanto ao meio quanto ao público, e suas expectativas. Assim, para Neder (1996, p. 73), “[...] o processo de avaliação da aprendizagem da $\mathrm{EaD}$, embora possa sustentar em princípios análogos aos da educação presencial, exige tratamento e considerações especiais", e sugere um processo contínuo e processual.

Seguindo com o pensamento de Neder (1996), a avaliação da aprendizagem na EaD é um processo que também requer um aluno autônomo, com capacidade de trabalhar uma complexidade maior de competências cognitivas, influenciando a construção do pensamento, por meio de caminhos que o próprio aluno desenvolve, sob o acompanhamento e direcionamento da equipe formada por professores e tutores. Por isso, na EaD existem várias concepções avaliativas. No entendimento de Mercado (2008, p. 1), a avaliação:

[...] é formativa, vista como um caminho a ser trilhado na construção e reflexão do conhecimento, no respeito ao saber e ao cotidiano dos alunos e na retomada da aprendizagem, por oferecer vantagens como: feedback imediato, flexibilidade 
na data de realização das atividades, respeito ao ritmo individual do aluno, abordagem modular, oportunidade de fazer cursos não oferecidos no local em que reside e utilização da Internet na ampliação de conhecimentos.

No entanto, os estudos de Mercado (2008) apresentam algumas possibilidades e ferramentas para a avaliação em cursos de $\mathrm{EaD}$, destacando as que considera principais: mapas cognitivos, memorial, blogs, fóruns de discussão e chats. Esses e outros recursos podem favorecer a prática avaliativa a distância; no entanto, o que está subjetivo ao processo de avaliação é mais importante para o contexto da educação superior em $\mathrm{EaD}$, conforme já mencionado no decorrer do artigo.

Destaca-se ainda que, ao olharmos para a avaliação na EaD, talvez o principal ponto de diferenciação da sala de aula presencial seja o uso dos aparatos tecnológicos. No entanto, dependendo do contexto, os mesmos poderão ser utilizados também na educação presencial.

\section{A PERSPECTIVA DA EDUCAÇÃO SUPERIOR}

No presente estudo, optou-se tomar por base o conceito de universidade proposto por Santos (2011) e de emancipação e autonomia, conforme sua finalidade, de acordo com Saul (2008) e Freire (1996; 1987), que também abordam o tema da opressão, entre outros autores.

Ao passar por mudanças, a universidade e o Ensino Superior têm sido percebidos por “[...] diferentes rótulos: nos EUA como 'capitalismo acadêmico', na Europa como homogeneização da educação superior e, na América Latina, como mercantilização e comoditização da educação superior pública”. (SERAFIM, 2011, p. 242). No Brasil, se inicia com uma prática neoliberal e se mantém aceita tanto por educadores quanto por educandos.

Na visão de Rodrigues (2007, p. 16), em comentário sobre as instituições de ensino superior (IES), "[...] pode ser nitidamente detectada uma tendência com duas faces das IES privadas se transformarem em efetivas empresas de ensino [...], buscando adaptar seu produto às demandas do capital produtivo".

Quando universidades se tornam um negócio, a educação passa a ser um produto, que precisa ser consumido em um mercado disputado; com isso, reduz-se o investimento em salário de professores e, com a possibilidade de $\mathrm{EaD}$, professores passam a ser substituídos por tutores, reduzindo assim sua participação nas disciplinas. Certamente, esse é o diferencial competitivo de algumas instituições de ensino, mas fica o questionamento sobre a qualidade na EaD. A avaliação da aprendizagem tem importante papel nessa verificação.

Ao pensar universidades, centros universitários, faculdades e instituições de Ensino Superior como mercados, percebe-se a competitividade por espaços de atuação dos professores e a cobrança de que precisam atender à pontuação, positivamente, nas avaliações do MEC, da Capes e em todos os rankings estabelecidos para a educação superior, inclusive no que se refere a publicações científicas, em renomados periódicos nacionais e internacionais.

Contudo, alterações no formato das aulas e de como os cursos são pensados, bem como a redução dos salários praticados, afetam educadores e educandos. Como afirma Chauí (1999, p. 3):

[...] o aumento insano de horas-aula, a diminuição do tempo para mestrados e doutorados, a avaliação pela quantidade das publicações, colóquios e congressos, a multiplicação de comissões e relatórios etc. virada para seu próprio umbigo, mas sem saber onde este se encontra, a universidade operacional opera e por isso mesmo não age. 
Inclusive, imersos nesses fazeres, os educadores tornam-se oprimidos, não refletem sobre seu formato, não pensam na mudança. Enquanto isso, há um crescimento da educação como mercadoria, que esmaga e oprime os educadores, que não o pensaram, por isso se submetem a essa lógica do capital e da competição entre instituições de ensino. "Mais uma vez os homens, desafiados pela dramaticidade da hora atual, se propõem a si mesmos como problema". (FREIRE, 1987, p. 29). Aspiram dar conta de suas demandas; afinal, se não são capazes disso são vistos como incompetentes.

Cientes de que a educação superior contribui para a formação de cidadãos críticos, politizados, democráticos e participativos, na condição de sujeitos ativos e reflexivos, torna-se essencial pensar sobre a finalidade da universidade no século XXI, e sobre seu papel diante da formação do cidadão, do pesquisador por ela preparado e na qual atua. Isto porque as universidades contribuem para a formação das novas sociedades e, consequentemente, da História humana.

As universidades são produtoras de conhecimento e tecnologia, mas também precisam sobreviver, necessitam de investimentos. Os recursos financeiros para universidades, centros universitários e outras instituições de ensino públicas são cada vez mais escassos e, por esse motivo, o governo destina parte de suas obrigações à universidade à iniciativa privada. Logo "[...] o favorecimento dado às universidades privadas decorre de elas se adaptarem muito mais facilmente às novas condições e imperativos" (SANTOS, 2011, p. 20) e, em muitos casos, representam a "venda" do conhecimento científico e tecnológico. Desse modo, o ciclo continua e a demanda de diferenças sociais causadas pela visão capitalista permanece em cena.

Nesse âmbito, estão as tecnologias produzidas por meio do conhecimento científico e utilizadas no ensino. Com a inserção tecnológica e a internet, as universidades expandiram seu entorno, atingindo alunos até de outros países, o que lhes permite ultrapassar fronteiras, sem sair de casa. E, nessa abertura de mercado, as possibilidades "[...] incluem educação a distância, aprendizagem online, universidades virtuais". (SANTOS, 2011, p. 23).

Esses fatos - abertura de mercado, tecnologias, universidades virtuais - contribuem, de alguma forma, para o crescimento acelerado do mercado do Ensino Superior. De um lado, as pessoas buscam formação para atender às exigências do mercado; de outro, as instituições de ensino buscam facilitar o acesso dos alunos, via tecnologias e oferta de EaD, a cursos com menor tempo de duração.

Sob essa mesma lógica, Santos (2011, p. 29, 30) enfatiza que “[...] a universidade produz conhecimento que a sociedade aplica ou não, uma alternativa que, por mais relevante que seja socialmente, é indiferente ou irrelevante para o conhecimento produzido". E afirma que esse tipo de conhecimento moldou as universidades e, inclusive, gerou uma mudança: a "[...] passagem do conhecimento universitário para o conhecimento pluriversitário". Explicita que "[...] o conhecimento pluriversitário tem tido a sua concretização mais consistente nas parcerias universidade = indústria e, portanto, sob a forma de conhecimento mercantil".

O termo pluriversitário refere-se à nova universidade, que continua com foco em pesquisa e na produção de conhecimento científico válido, que também vai gerando desenvolvimento econômico. Para Santos (2011), o problema é não haver espaço para outro tipo de geração de conhecimento científico útil, que não seja apenas o da geração de riqueza e de renda, mas que haja espaço também para a manutenção de culturas, desenvolvimento do ser humano e outras demandas vinculadas à qualidade da educação.

A responsabilidade das universidades e da educação superior, para além do desenvolvimento econômico, está na formação de cidadãos, de alunos autônomos, emancipados, críticos, que participem da sociedade de forma ativa, evitando o domínio e a corrupção tão em 
voga no Brasil. O que permite, nesse momento, acrescentar a contribuição de Freire (1996), com a pedagogia da autonomia.

O papel do educador, segundo Freire (1996, p. 16), é potencializar o desenvolvimento crítico e a autonomia de seus educandos numa perspectiva libertadora. É comum falar sobre essa pedagogia como progressista, que, do mesmo modo que a ética, deve permear toda a sua trajetória educativa: "[...] estar longe, ou pior, fora da ética, entre nós, mulheres e homens, é uma transgressão".

$\mathrm{Na}$ mesma perspectiva, educar é formar moralmente, é ensinar a pensar e é exemplo. "Não é possível ao professor pensar que pensa certo, mas ao mesmo tempo perguntar ao aluno se 'sabe com quem está falando" (FREIRE, 1996, p. 16); o educador deve pensar sobre seu fazer, um pensar certo, que dê o exemplo, uma reflexão crítica sobre sua própria prática. (FREIRE, 1996).

O fazer docente envolve conhecer, transmitir segurança e confiança sobre o que se ensina e, acima de tudo, em ser verdadeiro com os educandos, ser crítico, respeitando-os para ser respeitado, mostrando-lhes o que é e em que acredita, permitindo que eles também o façam. Para ensinar, diz Freire (1996, p. 37), é preciso primeiro aprender, e quem ensina também aprende no contato com os educandos. Destaca: "Nunca me foi possível separar em dois momentos o ensino dos conteúdos da formação ética dos educandos. A prática docente que não há sem a discente é uma prática inteira. O ensino dos conteúdos implica o testemunho ético do professor".

Uma prática educativa formadora de autonomia permite aos educandos, mesmo na universidade, constituírem-se pessoas com autonomia, essencial autonomia de pensamento, criticidade, emancipados dos domínios políticos que não se importam com a educação em si.

Respeito, ética, autonomia e avaliação ocorrem por meio de uma prática pedagógica alegre e estimulante. "A atividade docente de que a discente não se separa é uma experiência alegre por natureza." (FREIRE, 1996, p. 53). Entende-se que educar ou ser educado pode ser uma experiência alegre, divertida, em que educando e educador estão juntos, vivendo a experiência em si.

Para Saul (2008, p. 22), “[...] o paradigma da avaliação emancipatória inclui os conceitos de emancipação, decisão democrática, transformação e crítica educativa". Com isso é possível compreender o termo autonomia de fato, pois decidir democraticamente, chegando a um consenso do que será realizado, em termos de avaliação, consiste em mudança, transformação. Assim, educandos e educadores autônomos serão críticos em relação a uma avaliação que seja emancipatória, pois liberta educandos.

\section{CONSIDERAÇÕES FINAIS}

Este artigo desenvolveu um estudo reflexivo sobre as demandas da avaliação da aprendizagem na $\mathrm{EaD}$, na perspectiva da educação superior. Buscou-se analisar a avaliação da aprendizagem; entender o contexto em que está inserida, a interação e as demandas provenientes de suas particularidades na EaD e, ainda, a interferência ocasionada pelas mudanças que a educação vem enfrentando, no sentido mercadológico, que visa à exclusiva preparação para o trabalho.

A avaliação da aprendizagem remete a reflexões educativas acerca de valor justo, acerca de um mérito que seja somativo; que valorize o percurso de aprendizagem dos educandos, e que vise ao desenvolvimento da criticidade do aluno, para se tornar cidadão participativo e atuante na sociedade. Entende-se que a prática avaliativa na educação pode contribuir para a aprendizagem, para a formação de um sujeito autônomo, para emancipá-lo enquanto sujeito social.

Dessa forma, a avaliação da aprendizagem na EaD é pensada para além da mera reprodução de conteúdos, da avaliação da qualidade dessa modalidade, pois os estudantes não se encontram numa mesma sala de aula, frente a frente, pelo menos não sem o aparato tecnológico que propicia 
a EaD. E é nessa questão tecnológica que se percebe e se evidencia a prática avaliativa a distância do processo de aprendizado. Embora a legislação exija que a avaliação seja presencial nessa modalidade, evitando fraudes, muitos são os momentos interativos entre educador e educandos, os quais permitem, inclusive registro avaliativo e que podem vir a somar no quesito aprendizado, quando estão permeados por metodologias e planejamento.

E, na perspectiva da educação superior, encontra-se um mercado de educação, em que Instituições de Ensino Superior têm visado a um negócio lucrativo, tendência mundial praticada também no Brasil. A oferta de cursos superiores a distância tem se expandido cada dia mais e, com isso, percebe-se também uma mudança em termos do que era conhecido como educação superior, até o momento. Isso modifica a concepção do termo universidade e amplia a competição, na medida em que a educação se torna um mercado.

Com isso, educadores, que até então buscavam alternativas na forma de avaliar, agora competem por seu cargo, porque a $\mathrm{EaD}$ reduz o número de professores. Com uma demanda de salários mais baixos, veem-se obrigados a trabalhar em horas não remuneradas, competir por um currículo melhor que o dos colegas, a fim de não perderem sua colocação e, ainda, a educarem em um novo formato, que por vezes aliena e oprime o próprio educador.

Como uma possibilidade de mudança, a pedagogia da autonomia poderia indicar um caminho em que educador e educandos se libertam, lutam por seus direitos e por uma educação de fato constituinte de autonomia. Mas, como fazê-lo, se nem mesmo os professores são autônomos e sentem-se oprimidos por universidades, órgãos reguladores, políticas, mudanças de mercado e pela própria educação?

Esse artigo, no entanto, compreende as necessidades e emergências de uma educação para a autonomia e de um conceito de universidade que torne educandos autônomos, conhecedores de seus direitos e deveres com a sociedade e, ainda, para contribuírem com a educação e valorização dos educadores e da comunidade acadêmica. Afinal, juntos podemos mais!

\section{REFERÊNCIAS}

BARDIN, Laurence. Análise de conteúdo. Lisboa: Lisboa Edições 70, 2004.

BOURDIEU, Pierre. The economics of linguistic exchanges. Tradução de Paula Montero. Social Science Information, n. 16, p. 645-668, dec. 1977.

BRASIL. Lei de Diretrizes e Bases da Educação Nacional, n. 9.394, de 20 de dezembro de 1996. LDB. Disponível em http://portal.mec.gov.br/seesp/arquivos/pdf/lei9394 ldbn1.pdf. Acesso em 29 mar. 2017.

BRASIL. Decreto n. 5.622, de 19 de dezembro de 2005. Brasília, DF: Casa Civil, 19 dez. 2005. Disponível em http://www.planalto.gov.br/ccivil 03/ Ato20042006/2005/Decreto/D5622.htm. Acesso em 2 fev. 2020.

BRASIL. Decreto n. 9.057, de 25 de maio de 2017. Regulamenta o Art. 80 da Lei n. 9.394, de 20 de dezembro de 1996. LDB. Disponível em http://www.planalto.gov.br/ccivil 03/ ato20152018/2017/decreto/D9057.htm. Acesso em 30 ago. 2017.

CHAUÍ, Marilena. A universidade operacional. Folha de S. Paulo, São Paulo, 9 maio 1999. Caderno Mais.

DIAS SOBRINHO, José. Avaliação educativa: produção de sentido com valor de formação. Avaliação, Campinas, v. 13, n. 1, p. 193-207, mar. 2008. 
DILIGENTI, Marcos Pereira. Avaliação participativa: no ensino superior e profissionalizante. Porto Alegre: Mediação, 2003.

FREIRE, Paulo. Pedagogia da autonomia: saberes necessários à prática educativa. 25. ed. São Paulo: Paz e Terra, 1996.

FREIRE, Paulo. Pedagogia do oprimido. 19. ed. Rio de Janeiro: Paz e Terra, 1987.

HAYDT, Regina Cazaux. Avaliação do processo ensino-aprendizagem. 6. ed. São Paulo: Ática, 1997.

HOFFMAN, Jussara. Avaliação: mito e desafio: uma perspectiva construtivista. Porto Alegre: Mediação, 2005.

HOFFMAN, Jussara. Avaliação mediadora: uma prática em construção da pré-escola à universidade. 10. ed. Porto Alegre: Mediação, 1997.

HOFFMAN, Jussara. Avaliação mediadora: uma relação dialógica na construção do conhecimento.

Série Ideias, São Paulo, n. 22, p. 51-59, 1994. Disponível em http://www.crmariocovas.sp.gov.br/int a.php?t=008. Acesso em 10 abr. 2017.

KENSKI, Vani Moreira. Tecnologias e ensino presencial e a distância. 5. ed. Campinas: Papirus, 2008.

LIBÂNEO, José Carlos. Didática. 2. ed. São Paulo: Cortez, 1994.

LUCKESI, Carlos Cipriano. Avaliação da aprendizagem escolar: estudos e proposições. 19. ed. São Paulo: Cortez, 2008.

MEC/INEP. Censo da Educação Superior. 2018. Disponível em http://download.inep.gov.br/edu cação_superior/censo_superior/documentos/2019/apresentacao_censo_superior2018.pdf. Acesso em 9 dez. 2019.

MERCADO, Luís Paulo Leopoldo. Ferramentas de avaliação na educação on-line. 2008. Disponível em http://www.ufrgs.br/niee/eventos/RIBIE/2008/pdf/ferramientas avalua cion.pdf. Acesso em 26 ago. 2017.

NEDER, Maria Lúcia Cavalli. Avaliação na educação a distância: significações para a definição de percursos. NEAD - UFTM, 1996. Cuiabá. Disponível em http://www.nead.ufmt.br/. Acesso em 3 out. 2016.

PAVIANI, Jaime. Epistemologia prática: ensino e conhecimento científico. Caxias do Sul: EDUCS, 2009.

PERRENOUD, Philippe. Avaliação da excelência à regulação das aprendizagens: entre duas lógicas. São Paulo: Artmed, 1999.

RODRIGUES, José. Os empresários e a educaşão superior. Campinas: Autores Associados, 2007.

SANTOS, Boaventura de Sousa. A universidade do século XXI: para uma reforma democrática e emancipatória da Universidade. 3. ed. São Paulo: Cortez, 2011.

SANTOS, Clóvis Roberto dos et al. Avaliação educacional: um olhar reflexivo sobre sua prática. São Paulo: Ed. Avercamp, 2005.

SAUL, Ana Maria. Na contramão da lógica do controle em contextos de avaliação: por uma educação democrática e emancipatória. Educação e Pesquisa, [s. 1.], v. 41, p. 1299-1311, dez. 2015. FapUNIFESP (SciELO). Disponível em http://dx.doi.org/10.1590/S1517-9702201508143035.

SAUL, Ana Maria. Referenciais freireanos para a prática da avaliação. Revista de Educação PUCCampinas, Campinas, n. 25, p. 17-24, nov. 2008. Mensal.

SAUL, Ana Maria. A avaliação educacional. Série Ideias, São Paulo, n. 22, p. 61-68, 1994. Disponível em http://www.crmariocovas.sp.gov.br/int a.php?t=019. Acesso em 30 abr. 2017. 
SERAFIM, Milena Pavan. O processo de mercantilização das instituições de educação superior: um panorama do debate nos EUA, na Europa e na América Latina. Avaliação, Campinas; Sorocaba, São Paulo, v. 16, n. 2, p. 241-265, jul. 2011.

VYGOTSKY, Lev Semyonovich. A formação social da mente. São Paulo: Martins Fontes, 1998.

\section{Informações das autoras}

Vialana Ester Salatino

Universidade de Caxias do Sul (UCS)

E-mail: vialana.psicologia@gmail.com e/ou vesalati@ucs.br

ORCID: https://orcid.org/0000-0002-2582-9611

Link Lattes: http://lattes.cnpq.br/3758128605791855

Andréia Morés

Universidade de Caxias do Sul (UCS)

E-mail: anmores@ucs.br

ORCID: https://orcid.org/0000-0002-6982-0803

Link. Lattes: http://lattes.cnpq.br/9013852289503690 